Hydrology and Earth System Sciences, 8(5), 891-902 (2004) C EGU

\title{
Recession-based hydrological models for estimating low flows in ungauged catchments in the Himalayas
}

\author{
H.G. Rees ${ }^{1}$, M.G.R. Holmes ${ }^{1}$, A.R. Young ${ }^{1}$ and S.R. Kansakar ${ }^{2}$ \\ ${ }^{1}$ Centre for Ecology and Hydrology, Wallingford, Oxfordshire, OX10 8BB, UK \\ ${ }^{2}$ Department of Hydrology and Meteorology, PO Box 406, Babar Mahal, Kathmandu, Nepal
}

Email for corresponding author: hgrees@ceh.ac.uk

\begin{abstract}
The Himalayan region of Nepal and northern India experiences hydrological extremes from monsoonal floods during July to September, when most of the annual precipitation falls, to periods of very low flows during the dry season (December to February). While the monsoon floods cause acute disasters such as loss of human life and property, mudslides and infrastructure damage, the lack of water during the dry season has a chronic impact on the lives of local people. The management of water resources in the region is hampered by relatively sparse hydrometerological networks and consequently, many resource assessments are required in catchments where no measurements exist. A hydrological model for estimating dry season flows in ungauged catchments, based on recession curve behaviour, has been developed to address this problem. Observed flows were fitted to a second order storage model to enable average annual recession behaviour to be examined. Regionalised models were developed, using a calibration set of 26 catchments, to predict three recession curve parameters: the storage constant; the initial recession flow and the start date of the recession. Relationships were identified between: the storage constant and catchment area; the initial recession flow and elevation (acting as a surrogate for rainfall); and the start date of the recession and geographic location. An independent set of 13 catchments was used to evaluate the robustness of the models. The regional models predicted the average volume of water in an annual recession period (1st of October to the 1st of February) with an average error of $8 \%$, while mid-January flows were predicted to within $\pm 50 \%$ for $79 \%$ of the catchments in the data set.
\end{abstract}

Keywords: Himalaya, recession curve, water resources, ungauged catchment, regionalisation, low flows

\section{Introduction}

The Himalayan regions of Nepal and northern India experience the full range of hydrological extremes. Up to $80 \%$ of the annual rainfall occurs during the monsoon (Thapa, 1993) and the corresponding peak flows during July/ September may be 10 to 40 times the average dry season flows of December/ February. While floods can cause acute disasters, including the loss of human life, property and infrastructure, the lack of water during the dry season has a chronic impact on the lives of local people, particularly as most of the population depend directly on agriculture for their livelihoods. Shortages of water during the dry season reduce yields from irrigated crops and threaten the food security of the region.

Integral to any effective water resource management is the quantification of the natural availability of water within a catchment area. In catchments where gauging stations exist and flow records are available, this assessment may be undertaken by analysing the observed hydrographs. Measures of the average volume of water available on an annual, or monthly, resolution and estimates of the variability of daily flows may be obtained directly from the observations. However, the network of gauged catchments is very sparse in the Himalayas and estimates of resource availability are commonly needed in ungauged catchments. Hence, there is a requirement for regionalised hydrological models that estimate resource availability, based on readily obtainable catchment characteristics.

\section{Background}

To predict aspects of Himalayan flow regimes, a number of models have been developed; many to assess the hydropower potential of ungauged catchments. For example, 
the Water and Energy Commission Secretariat of Nepal estimated flow duration statistics in ungauged catchments in Nepal using linear regression-based models (WECS, 1990). In north-western India, Singh et al. (2001) developed regional flow duration curves for nine regions in the Himalayas for planning micro-hydropower projects. A regionalised flow estimation method was developed by Rees et al. (2002) to enable flow duration curves to be estimated using catchment characteristics in rain and snow-fed zones of both Himachal Pradesh (India) and Nepal.

The use of flow duration statistics enables exceedence probabilities to be assigned and, hence, the dependability of a given flow can be assessed. However, from a water resources perspective, the temporal sequencing of flows is also important. Approximately $90 \%$ of the water abstracted in Asia is associated with irrigated agriculture (FAO United Nations, 1999); this usage commonly coincides with the dry season, when competing demands for water reach a peak. Hence, the ability to assess the availability of water throughout the agricultural calendar is important for effective management of water resources in the region.

One approach to studying dry season flows is recession curve analysis. Within the hydrograph, recessions are a sequence of progressively decreasing flows during periods with little or no rainfall. This represents water being removed naturally from the catchment via a complicated combination of soil and groundwater drainage processes and evapotranspiration. The rate of decrease in flow is affected by factors including hydrogeology, soil types, topography, climate, catchment size and slope. Boussinesq (1877) used recession curves to describe groundwater flow and Hall (1968) defined baseflow and described baseflow recession behaviour. Recently, Moore and Bell (2002) used recession analysis to model intermittent streamflow and the impacts of groundwater pumping in English chalk catchments. Recession analysis has also been used to define drainage parameters in hydrological models (Harlin, 1991) and Delft (1995) used observed recession behaviour to calibrate slow flow drainage coefficients in a two-layer Sacramento rainfall runoff model. A detailed review of baseflow recession analysis can be found in Tallaksen (1995).

Recession curve analysis is suited for defining dry season flows in the Himalayas due to the regular and uninterrupted nature of the post-monsoon recessions that occur in the region. The river flows during these periods reflect the characteristic drainage of catchment storages, which is rarely interrupted by significant rainfall events. Recession behaviour is very predictable, with low between-year variability and, hence, the average annual recession would provide a good measure of resource availability during an average dry season. Furthermore, analysis of dry season flows separately from the entire hydrograph reduces the impact of the hydrometric uncertainties associated with measurement of high flows during the monsoon season.

\section{Recession analysis}

Hydrological recessions are conceptualised as everdecreasing flows that result from drainage of catchment storages during periods of little or no precipitation inputs. The outflow from a conceptual catchment store during a recession period is assumed to be proportional to a power of the volume of water stored within the catchment;

$$
\mathrm{q}=\mathrm{k} \mathrm{S}^{\mathrm{m}} \quad \mathrm{k}>0, \mathrm{~m}>0
$$

where $\mathrm{q}=\mathrm{q}(\mathrm{t})$ is the outflow at time $\mathrm{t}$, $\mathrm{k}$ is the recession constant, $\mathrm{S}=\mathrm{S}(\mathrm{t})$ is the storage at time $\mathrm{t}$, and $\mathrm{m}$ is an exponential describing the form of the storage $(\mathrm{m}=1$ for $\mathrm{a}$ linear store, $\mathrm{m}=2$ for quadratic store, etc.).

When this is combined with the continuity equation;

$$
\mathrm{dS} / \mathrm{dt}=\mathrm{u}-\mathrm{q}
$$

Where $\mathrm{u}=\mathrm{u}(\mathrm{t})$ is the input (i.e. effective rainfall) to the catchment store then the general Horton-Izzard (Dooge, 1973) model describing the rate of change of flow from the catchment store can be derived as follows:

$$
\begin{aligned}
& \mathrm{dq} / \mathrm{dt}=\mathrm{a}(\mathrm{u}-\mathrm{q}) \mathrm{q}^{\mathrm{b}} \\
& \text { where } \\
& \mathrm{a}=\mathrm{mk}^{1 / \mathrm{m}} \\
& \text { and } \\
& \mathrm{b}=(\mathrm{m}-1) / \mathrm{m}
\end{aligned}
$$

A special case of Eqn. 3 exists when inflows are assumed to be zero, which is to say that the catchment experiences no effective rainfall during the recession period. The validity of this assumption was assessed across a selection of Himalayan catchments for which rainfall data were available. It was found that rainfall events tended either to be significant enough to signal the end of the recession period or insufficient to impact on the observed shape of the recession curve. Similar observations had been made by Boorman et al. (1996) who were able to collect high resolution (30 minute) rainfall data. Hence, it was concluded that zero inflows could be assumed and Eqn. 3 as shown by Gill (1976 and 1977) reduce to Eqn. 4 for the case of a linear store, and Eqn. 5 for a non-linear store. 


$$
\begin{aligned}
& \mathrm{q}_{\mathrm{t}+\mathrm{T}}=\exp (-\mathrm{kT}) \mathrm{q}_{\mathrm{t}} \\
& \mathrm{q}_{\mathrm{t}+\mathrm{T}}=\left[\mathrm{q}_{\mathrm{t}}^{-\mathrm{b}}+\mathrm{a} \cdot \mathrm{b} \cdot \mathrm{T}\right]^{-1 / \mathrm{b}}
\end{aligned}
$$

\section{MODEL DEVELOPMENT}

The suitability of the theoretical recession models for application in the Himalayas was examined using a dataset of catchments from rain and snow fed regions of Himachal Pradesh (India) and Nepal. Only catchments with natural flow regimes and a minimum of ten years' flow data were considered: 39 catchments were identified and each full hydrograph was inspected and quality controlled. The data set was divided into 26 'calibration' catchments, to develop the recession models, and 13 'evaluation' catchments that comprised an independent test data set, see Fig. 1.

Mean daily flow measurements for the Nepalese catchments were reduced to ten-day average data, to be consistent with the format of the flow data available for Himachal Pradesh. Automated procedures identified recession periods from hydrographs using the following criteria; a recession was defined to begin at the third consecutively decreasing flow value and to end at the first increasing flow value; a minimum recession length of 100 days (ten 10-day flow values) was set to ensure that only the main, annual recession was identified. These criteria were similar to those used by authors such as Vogel and Kroll (1992). Examples of annual recessions derived by the automated methods are shown in Fig. 2.

Annual recessions for the calibration catchments were identified in this manner and fitted to model forms described by Eqns. 4 and 5 using linearisation techniques. The goodness of fit was assessed for discrete values of $\mathrm{m}=1,2$ and 3 to determine the most appropriate storage model. The storage coefficient (m) in Eqn. 3 defines the conceptualisation of the drainage behaviour of the catchment store. Considering overland flow, Horton (1945) showed that fully laminar flow conditions are represented by the third order storage case $(\mathrm{m}=3)$ and for fully turbulent flow conditions, $\mathrm{m}=5 /{ }_{3}$. Following the Werner and Sundquist (1951) theoretical analysis of flow from a deep unconfined aquifer, based on Darcy's Law and the Dupuit's assumption, Ding (1967) concluded that the quadratic storage function $(\mathrm{m}=2)$ was appropriate for this type of groundwater flow. The current study suggested that a second order model performed consistently better than a linear storage model and comparably to a third order model. No relationship could be identified between storage coefficient and catchment characteristics and so a second order model was considered applicable for the study areas.

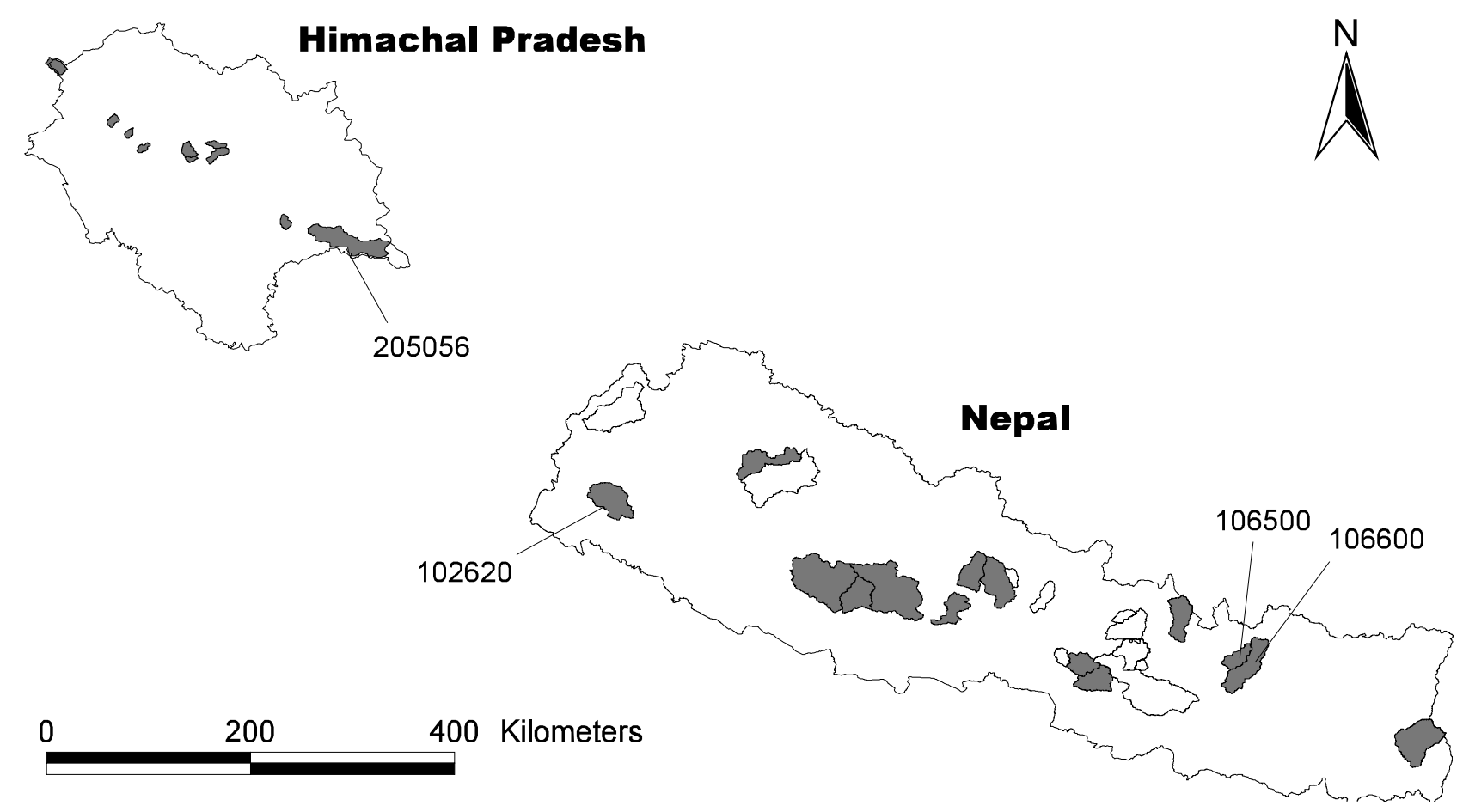

Fig. 1. Location of catchments in the calibration $(n=26$, shaded) and evaluation ( $n=13$, non-shaded) data sets 


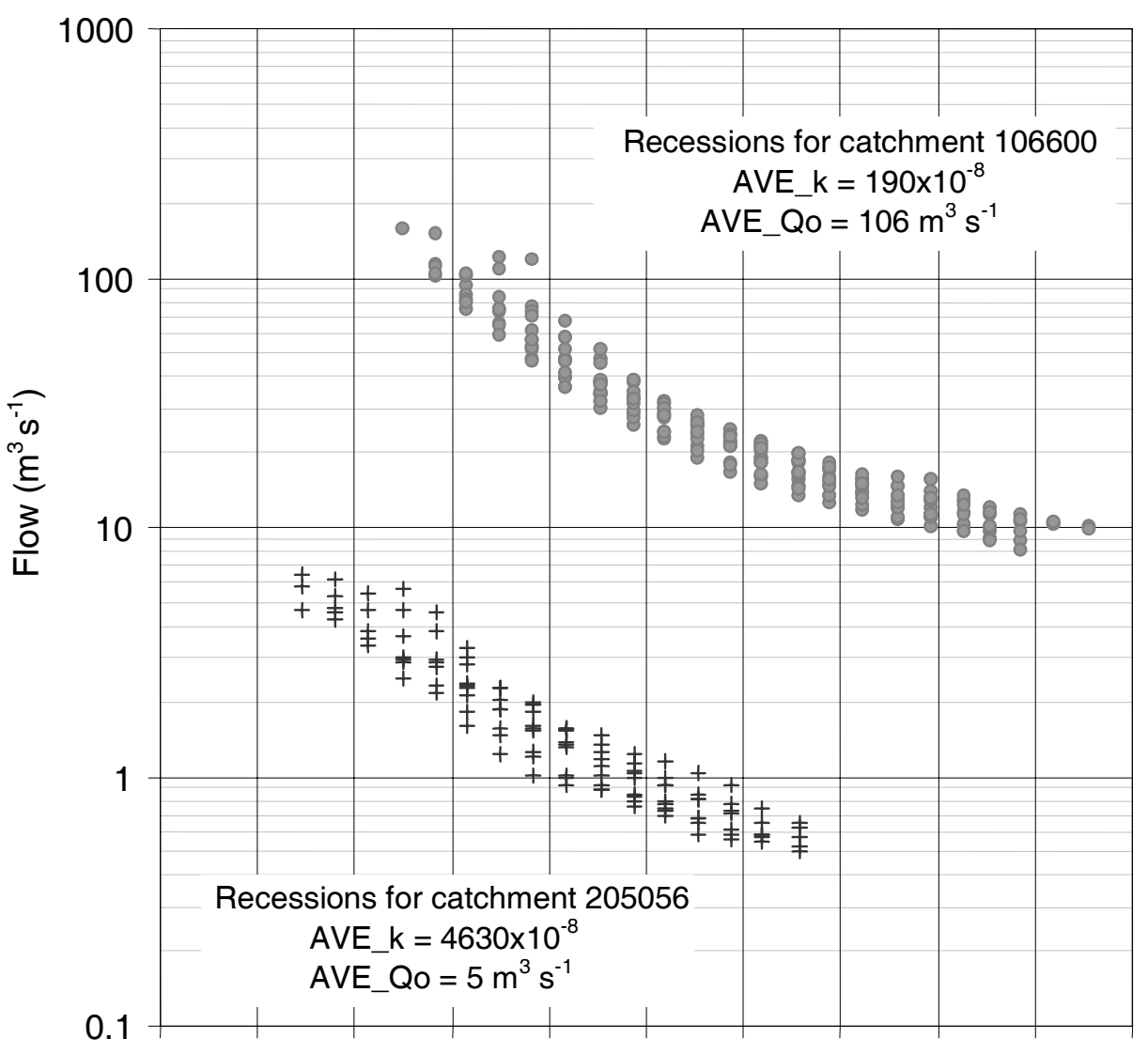

Fig. 2. Examples of annual recessions identified by automated procedure

The annual recessions, fitted to a linearised form of the quadratic form of Eqn. 5, enabled average values of the three key recession parameters to be identified for each year of data: the storage coefficient $(\mathrm{k})$, the initial recession flow $\left(\mathrm{Q}_{\mathrm{o}}\right)$ and the start date for the recession $\left(\mathrm{T}_{\mathrm{o}}\right)$. These values were then averaged across all years of data for a given catchment to give an average annual recession parameter. The range and average values of these average parameters across the data set are shown in Table 1.

Given the relatively small data set and existence of only a few recessions in some catchments, the between-year variability of recession parameters was tested to assess whether the observed between-catchment variations in average parameter values could be due purely to sampling errors. A matrix of t-tests was performed for each possible combination of catchments in the data set. At a $95 \%$ confidence level $73 \%$ of the combinations of catchments had significantly different values of AVE_k, 50\% of combinations had significantly different values of AVE_ $Q_{0}$ and $40 \%$ of combinations had significantly different values of AVE_ $T_{0}$. This suggested that the variability of the AVE $k$ and AVE_ $\mathrm{Q}_{\mathrm{o}}$ were unlikely to be due to sampling error, but that the variability of AVE_T may be, in some instances. Hence, to explain the variation of these recession curve parameters across the data set, development of models was warranted.

\section{Regionalised models for recession curve parameters}

Regionalisation of recession curve parameters by developing relationships between these variables and catchment characteristics would enable the recession curve model to be applied in ungauged catchments. Relationships between the observed average recession parameters and catchment characteristics were examined over the calibration data set using Spearman rank correlation analysis. The relationships thus identified were then examined for intercorrelation with other catchment characteristics, Table 2.

Multivariate-linear regression techniques were used to develop relationships between the recession parameters and catchment characteristics using transformed and untransformed variables, see Table 3 . The final models and 
Table 1. Statistics for observed average annual recession curve parameters for the full data set $(n=39)$

\begin{tabular}{l}
\hline Parameter $\quad$ Box plots \\
\hline
\end{tabular}

Storage coefficient

AVE k $\left(\times 10^{-8}\right)$

$\operatorname{Max}=80512$

Min $=113$

Average $=3404$

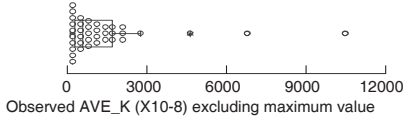

Initial Recession Flow

AVE_Qo $(\mathrm{mm})^{[2]}$

$\operatorname{Max}=700$

Min $=86$

Average $=273$

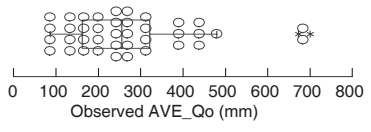

Start Date

AVE_To (days) ${ }^{[3]}$

$\operatorname{Max}=291$

Min $=222$

Average $=261$

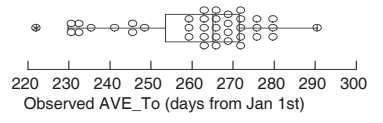

Notes:

[1] Box plots - centre vertical line marks the median of the sample and length of each box shows the range within which the central $50 \%$ of the values fall, with the box edges (hinges) at the first and third quartiles, the whiskers from the hinges to \pm 1.5 times the inter-quartile range.

[2] AVE_Qo is the ten day average flow value expressed as an equivalent depth per unit area

[3] AVE_To is expressed as number of days from January $1^{\text {st }}$

expressions of model fit over the calibration data set are also shown.

Catchment 102620 was identified as an outlier (Studentised residual of 5.4) in Model A and the recessions from this catchment represented one of the poorest fits to the second order storage model assumed. Catchment 106500 was identified as an outlier (Studentised residual of 4.7) in Model B and investigations revealed that this catchment exhibits atypical runoff behaviour, generating almost twice the observed average annual runoff of a neighbouring catchment 106600 , possibly due to hydrometric error or errors in catchment delineation. These outliers were excluded from the development of the respective models. Standard checks of parameter collinearity, parameter significance and distributions of residuals were made.

\section{EVALUATION}

The regional models were evaluated using an independent test set of 13 catchments. The performance of the regional models with the calibration and evaluation data sets is summarised in Table 4. The performance indicators, root mean squared error (RMSE) and average standardised residual (BIAS), reflect the random and systematic components of error in the models, (Eqns. 6 and 7).

$$
\begin{aligned}
& R M S E=\sqrt{\frac{1}{n} \sum_{i=1}^{n}\left(X_{O B S}^{i}-X_{P R E D}^{i}\right)^{2}} \\
& B I A S=\frac{1}{n} \sum_{i=1}^{n}\left(\frac{X_{O B S}^{i}-X_{P R E D}^{i}}{X_{O B S}^{i}}\right)
\end{aligned}
$$

where $\mathrm{X}_{\text {OBS }}^{\mathrm{i}}$ is the observed parameter value and $\mathrm{X}_{\text {PRED }}^{\mathrm{i}}$ is the predicted parameter value for catchment ' $i$ ', evaluated over all ' $n$ ' catchments.

The results suggest that the regional models are relatively robust as the performance over the evaluation data set is comparable to that over the calibration data set, see also Fig. 3. Catchments within the evaluation data set contained values of both the observed recession parameters and the explanatory catchment characteristics, which were outside the ranges of these variables shown in the calibration data set. Hence, assessment of the regional models over this evaluation data set represents a harsh test as they are being extrapolated for use beyond the data range used to originally develop them. This resulted in the exclusion of an evaluation catchment from the assessment (105362) and prevents strong conclusions from being drawn regarding the robustness of the models. Outliers 104280, 105500 and 104393 were identified by Studentised residuals greater than 3 .

\section{DISCUSSION}

The average recession constant (AVE_k) was found to be most strongly correlated with catchment area. Larger catchments experience flatter recessions (smaller recession constants) which reflects the 'dampening' of the recession response in large catchments. This type of relationship between recession rates and scale has been noted by authors such as Wittenberg (1994) who suggested a relationship between non-linear recession constants and catchment area for a number of German and Chinese catchments. However, conceptually, recession rates reflect the physiography of a catchment and the underlying hydrogeology, with more permeable systems being associated with flatter recessions due to slower drainage rates. Such relationships have been suggested by Mansell and Johnson (1994) in Zimbabwe, by Pereira and Keller (1982) for Swiss Pre-Alp basins and by Demuth and Schrieber (1994) for German catchments. 
Table 2. Spearman correlation between observed average recession parameters and catchment characteristics (shading indicates the catchment characteristics adopted in the final regional models)

\begin{tabular}{|c|c|c|c|}
\hline Variable & $\begin{array}{l}\text { Catchment } \\
\text { characteristic }\end{array}$ & Description & $\begin{array}{l}\text { Spearman correlation } \\
\text { coefficient }\end{array}$ \\
\hline \multirow[t]{5}{*}{ AVE_k } & AREA & Catchment area in $\mathrm{km}^{2}$ & -0.844 \\
\hline & MEAN_ELEV & $\begin{array}{l}\text { Mean elevation of catchment based on a } 1 \times 1 \mathrm{~km} \text { elevation grid derived } \\
\text { from the USGS GTOPO30 data set (USGS, 1996) }\end{array}$ & 0.331 \\
\hline & MEAN_ASP & $\begin{array}{l}\text { Mean aspect, based on a derived } 1 \times 1 \mathrm{~km} \text { aspect grid of discrete values } \\
(360=\text { north, } 180=\text { south })\end{array}$ & -0.332 \\
\hline & MEAN_RAIN & $\begin{array}{l}\text { Catchment average annual rainfall }(\mathrm{mm}) \text { derived from a digitisation of } \\
\text { (ICIMOD, 1996) }\end{array}$ & -0.322 \\
\hline & FRAC_GT_4500 & $\begin{array}{l}\text { Fraction of the catchment area above an assumed permanent snow line } \\
\text { at } 4500 \mathrm{~m} \text {, derived from the } 1 \times 1 \mathrm{~km} \text { elevation grid }\end{array}$ & -0.049 \\
\hline \multirow[t]{5}{*}{ AVE_Qo } & AARD_OBS & $\begin{array}{l}\text { Observed average annual runoff depth, mean flow expressed as an } \\
\text { equivalent depth over the catchment }\end{array}$ & 0.913 \\
\hline & MEAN_ELEV & & 0.454 \\
\hline & CV_ELEV & $\begin{array}{l}\text { Coefficient of variation of elevation (standard deviation / mean) based } \\
\text { on the } 1 \times 1 \mathrm{~km} \text { elevation grid }\end{array}$ & 0.191 \\
\hline & MEAN_ASP & As above & 0.134 \\
\hline & MEAN_RAIN & As above & 0.084 \\
\hline \multirow[t]{7}{*}{ AVE_To } & LAT_CENT & Latitude of the centroid of the catchment & -0.714 \\
\hline & LNG_CENT & Longitude of the centroid of the catchment & 0.663 \\
\hline & DIST & $\begin{array}{l}\text { Geographical distance (decimal degrees) between the catchment } \\
\text { centroid at an origin at Latitude } 25.3^{\circ} \text { Longitude } 90.0^{\circ}\end{array}$ & -0.659 \\
\hline & MEAN_ELEV & As above & -0.769 \\
\hline & MIN_ELEV & $\begin{array}{l}\text { Minimum elevation of catchment based on a } 1 \times 1 \mathrm{~km} \text { elevation grid } \\
\text { derived from the USGS GTOPO30 data set (USGS, 1996) }\end{array}$ & -0.689 \\
\hline & SD_ELEV & Standard deviation of elevation within a catchment, based on the & \\
\hline & & $1 \times 1 \mathrm{~km}$ elevation grid & -0.355 \\
\hline
\end{tabular}

Table 3. Regional models for recession curve parameters

\begin{tabular}{|c|c|c|c|}
\hline Model & Regional model & Standard error & $R^{2}$ \\
\hline $\mathrm{A}^{[1]}$ & AVE_k $=57544 \times$ AREA $^{-0.793}$ & $1.45^{[2]}$ & 0.88 \\
\hline $\mathrm{B}$ & AVE_Qo $=128.743 \times$ CV_ELEV $+0.0215 \times$ MEAN_ELEV -4.393 & $27(\mathrm{~mm})$ & 0.41 \\
\hline $\mathrm{C}$ & AVE_To $=291.031-2.044 \times$ DIST $-0.008 \times$ MEAN_ELEV & 10.8 (days) & 0.61 \\
\hline \multicolumn{4}{|c|}{$\begin{array}{l}\text { Notes: } \\
\text { [1] AVE_k }\left(\times 10^{-8}\right) \\
\text { [2] The standard error is a factorial standard error, because the model for AVE_k is logarithmic }\end{array}$} \\
\hline
\end{tabular}

In this study, identification of relationships between catchment hydrogeology and recession rates was hampered by a lack of geological or hydrogeological data sets of suitable scale. Coarse geology classifications in Nepal, mapped at 1:1000 0000 scale, were used to examine possible relationships across the Nepalese catchments. However, no conclusive relationship could be found and catchments of very similar lithology exhibited very different recession rates and vice versa. Catchment area explained the underlying variability of the recession constant but was not correlated 

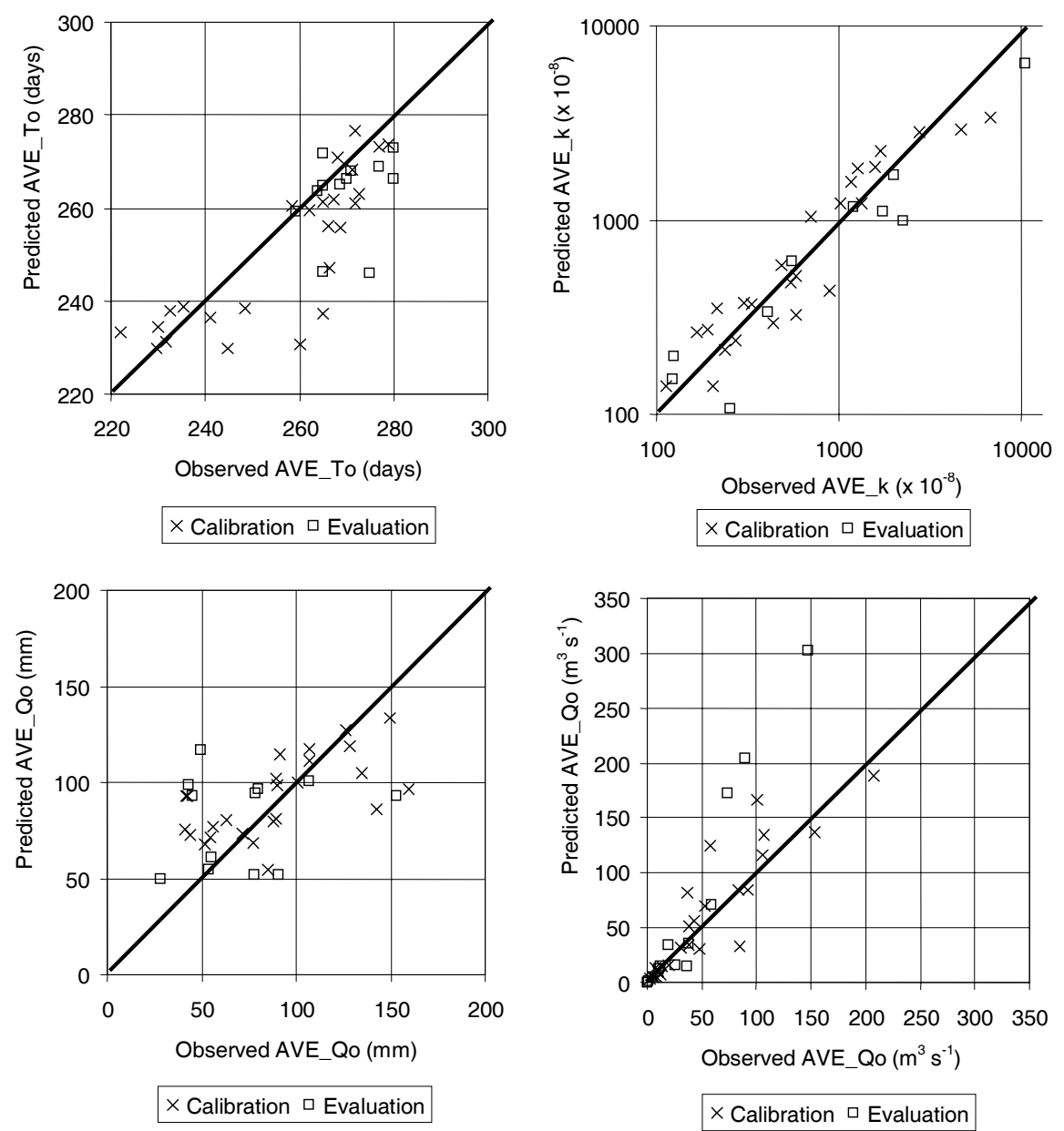

Fig. 3. Performance of regional models over calibration and evaluation data sets

Table 4. Performance of regional models over calibration and evaluation data sets

\begin{tabular}{lllll}
\hline Model & Performance indicator & Calibration $(n=26)$ & Evaluation $(n=13)$ & Comments \\
\hline AVE_k & & & & \\
& BIAS & -0.062 & 0.133 & Excluding outliers 102620, 104393, \\
& RMSE & 802.457 & 1365.406 & 105362 and 105500 \\
AVE_Qo & & -0.160 & -0.310 & Excluding outliers 106500 and 104280 \\
& BIAS & 27.587 & 37.137 & \\
AVE_To & RMSE (mm) & 0.025 & 0.028 & Excluding outliers 106500 and 104393 \\
& BIAS & 11.923 & 12.212 & \\
\hline
\end{tabular}

with the fractional extents of geological classes. To examine whether permanent snow and ice cover had an influence on recession rates, the fraction of the catchment above $4500 \mathrm{~m}$ elevation (FRAC_GT_4500) was used; the very weak correlations indicated this was not supported by the data.
Furthermore, as noted by Kinsel (1963), the relationship between recessions and geological factors is complex and will be influenced by site specific conditions. Such conditions include; the connectivity of aquifer and surface waters; the orientation of groundwater storages relative to 
stream networks; and the degree of fracture of confining material, none of which could be determined from the geological data sets available to this study. In a review of baseflow recession analysis, Tallaksen (1995) concludes that qualitative rather than quantitative descriptions of such relationships are more commonly reported by researchers.

The two-layer Sacramento rainfall runoff model developed by Delft Hydraulics (1995) for Western Nepal included a regional equation for predicting the slow flow recession constant, using catchment elevation as an explanatory variable. The equation suggests that high elevation catchments experienced more rapid rates of recession than low elevation catchments. However, in the data set available for this study, catchment area and mean elevation proved to be intercorrelated (Spearman correlation -0.26); higher elevation catchments tend to be headwater catchments and hence small in area. Therefore, in the Delft Hydraulics (1995) model, elevation may be acting as a surrogate for catchment area.

The very strong relationship found between the average initial recession flow and the average annual runoff (Spearman correlation of 0.91) suggests that the factors controlling the scale of the runoff processes may also control the initial recession flows. Higher initial recession flows could be expected in catchments experiencing higher than average annual runoff. Therefore, a relationship between AVE_ $Q_{0}$ and climatic variables could be expected. However, no such relationships were determined from the data available and the Spearman correlation for average annual rainfall was low (0.08). This may be because the use of a relatively coarse characterisation of rainfall (particularly in Himachal Pradesh), which is unable to reflect the true heterogeneity of climatic conditions caused by orographic effects and the massive variations in local relief.

The regional model for estimating the initial recession flows shows a weak relationship with topographic variables average elevation (MEAN_ELEV) and a measure of the variability of elevation (coefficient of variation CV_ELEV). High elevation catchments with significant variations in topography are associated with large initial recession flows. The elevation-based variables have been shown to act as surrogates for rainfall and climatic conditions in the region, Rees et al. (2002). While the nature of relationships between elevation and rainfall are complex, Singh et al. (1997) suggests rainfall increases to a maximum at approximately 1600 to $2200 \mathrm{~m}$ elevation and then decreases with increasing elevation thereafter. Within the Middle Himalayas there is a general increase of rainfall with elevation, which is consistent with the form of the regional model. Examination of the spatial distribution observed AVE_ $Q_{0}$ values for Nepalese catchments, where better quality average annual rainfall data were available, confirmed that annual rainfall explained approximately $50 \%$ of the variance in the model.

Hence, although the final adopted Model B explains only a small portion of the variance $\left(\mathrm{R}^{2}=0.41\right)$ this was the best relationship that could be determined from the available data sets. It is noted that the uncertainty associated with estimating initial recession flows in ungauged catchments using Model $\mathrm{B}$ is high. The understanding of initial recession behaviour would benefit from the collection of flow data during the post-monsoon period.

The timing of the start of the recession period is shown to be correlated with geographic location. The DIST variable reflects the distance of the catchment from the Bay of Bengal, where the monsoonal weather systems originate, and the model form indicates that recessions begin earlier in the most north-western catchments. This is supported by local observation and studies by authors, such as Chalise (1996), who notes that the monsoons withdraw from western Nepal earlier than eastern Nepal. The mean elevation (MEAN_ELEV) variable may reflect the weakening of the monsoon as it progresses in a northerly direction, noted by Kansakar et al. (2002) to be caused by orographic lifting over sucessive mountain ranges, which would correspond to recessions beginning earlier in the northern, higher elevation catchments.

\section{Model performance}

The combined performance of the regional models was assessed by comparison of observed average annual recessions with those predicted by the regional models. The observed average recessions were generated using the observed parameters AVE_k, AVE_ $Q_{o}$ and $\mathrm{AVE}_{-} \mathrm{T}_{\mathrm{o}}$ and, hence, represent the long term recession behaviour for a catchment fitted to the assumed model form (second order).

The measure BIAS ${ }_{\mathrm{VOL}}$ is a measure of the model's ability to replicate the volume of water passing through the catchment during a recession. This measure is important from a water resource management perspective, where the volumetric water requirements during recession periods must be compared with the natural supply. BIAS $\mathrm{V}_{\mathrm{VOL}}$ is calculated as the difference between the area under the observed and predicted recession curves (during the recession period), expressed as a fraction of the area under the observed recession, see Eqn. 8.

$$
B I A S_{V O L}=\frac{\sum_{i=1}^{n}\left(Q_{O B S}^{i}-Q_{P R E D}^{i}\right)}{\sum_{i=1}^{n} Q_{O B S}^{i}}
$$

where $\mathrm{Q}_{\mathrm{OBS}}^{\mathrm{i}}$ is the observed $10 \mathrm{~d}$ flow value at time ' $\mathrm{i}$ ' in 
cumecs, $\mathrm{Q}_{\text {PRED }}^{\mathrm{i}}$ is the predicted $10 \mathrm{~d}$ flow value at time ' $\mathrm{i}$ ' in cumecs, and the ' $n$ ' flow values considered are from the $1 \mathrm{st}$ of October to the 1st of February (inclusive), 13 individual $10 \mathrm{~d}$ flow values. This period covers the recession periods observed in the data set and, hence, represents the period at which competition for water resources will be at a peak.

Over the full data set $(n=39)$ the average BIAS $_{v o L}$ was found to be -0.08 suggesting that, on average, the annual recession volume between 1 st of October to the 1 st of February was over estimated by $8 \%$. This average error was halved if the six outlier catchments were excluded from the assessment. Of the 39 catchments, the BIAS ${ }_{\text {VOL }}$ was predicted to within $\pm 25 \%$ for 20 catchments, and to within $\pm 50 \%$ for 33 .

The two catchments where the regional model performs best (202111 and 107280) and worst (206041 and 102620) are illustrated in Fig. 4, which shows only the portion of the recession between the beginning of October to the end of February. The poor performance of the model in 102620 can be attributed to a poor estimation of the recession constant ' $\mathrm{k}$ '. This catchment was identified as an outlier during model development and recessions for this catchment were poorly described by the second order storage model. The model in 206041 performs poorly for a different reason: here the initial flow of the recession is estimated poorly. Analysis showed that the overall performance of models in predicting recession volumes was equally dependent on the success of the regional model for predicting AVE_k and the model for predicting AVE_ $\mathrm{Q}_{0}$.

To express the performance of the models in dimensionless terms the differences between the observed and predicted 10-day flow values were calculated as an equivalent depth over the catchment area. Use of the absolute sign of this difference $\left(\mathrm{ABSERR}_{\mathrm{DEPTH}}\right.$ ) removed any over- and underestimation cancelling out when expressed as a net error.

$$
A_{B S E R R_{D E P T H}}=\frac{3600 \times 24 \times 10 \times\left|Q_{O B S}^{i}-Q_{P R E D}^{i}\right|}{(1000 \times A R E A)}
$$

Where $\mathrm{Q}_{\mathrm{OBS}}^{\mathrm{i}}$ is the observed 10-day flow value at time ' $\mathrm{i}$ ' in cumecs, $\mathrm{Q}_{\text {PRED }}^{\mathrm{i}}$ is the predicted 10-day flow value at time ' $\mathrm{i}$ ' in cumecs, and AREA is the catchment area in $\mathrm{km}^{2}$.

Hence the average error, expressed as an equivalent depth, could be calculated for each of the 10-day flow periods between the 1st of October and the 1st of February (inclusive) is shown in Fig. 5. The average errors put the uncertainty of the regional models in perspective and show that the models are able to predict mid-January flows to

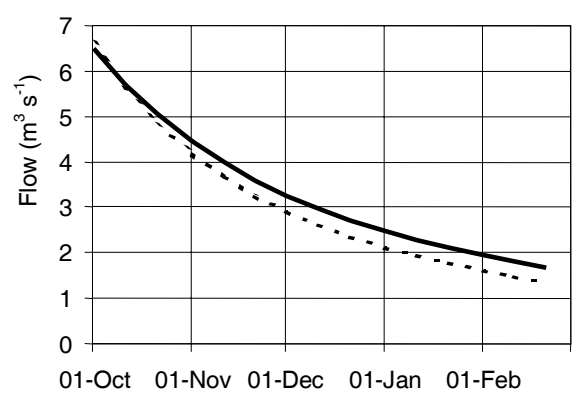

202111_OBS - - - 202111_PRED

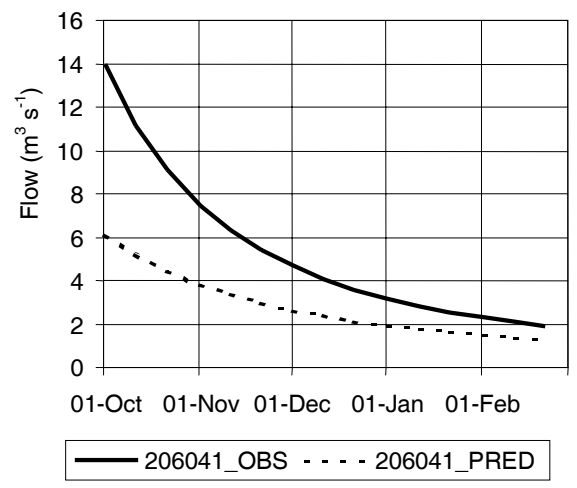

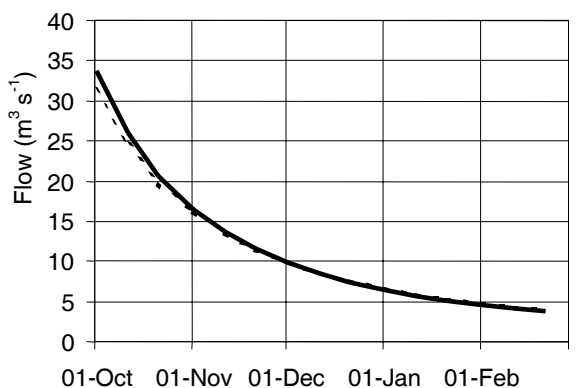

- 107280_OBS - . - 107280_PRED

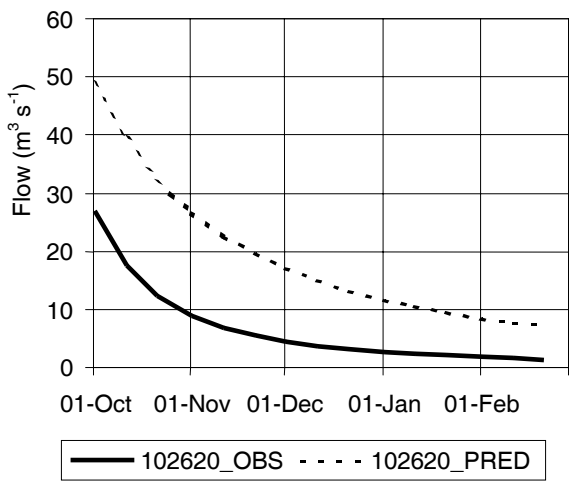

Fig. 4. Illustration of the best model performance in catchments 107280 and 202111 and the worst performance in 102620 and 206041 using predicted values of AVE $k, A V E$ Qo and AVE To over the period October 1st to February 1st 


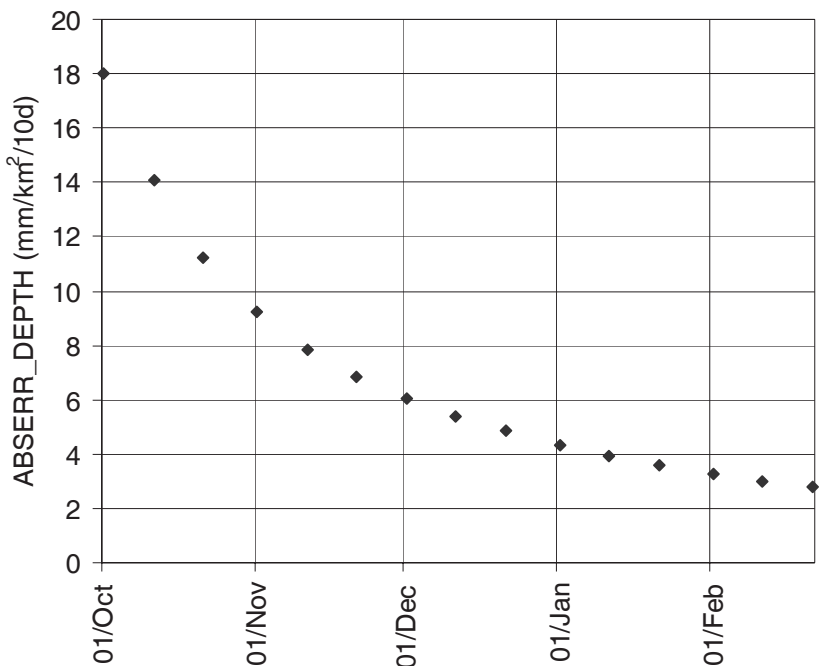

Fig. 5. The variation of average $A B S E R R_{D E P T H}\left(\mathrm{~mm} / \mathrm{km}^{2} / 10 d\right)$ for lod recession flows

within an error in flow representing an equivalent depth of only $4 \mathrm{~mm}$ across the catchment. The mid-January ABSERR $_{\text {DEPTH }}$ was found to be less than $5 \mathrm{~mm}$ for 27 of the 39 catchments.

A comparison of mid-month flows for December, January and February also illustrates the good performance of the regional models at estimating discrete flow values, see Fig. 6 . The mid-January flow was predicted to within $\pm 50 \%$ of the observed value, for 31 of the 39 catchments.

The ability of the long term average recession to describe the observed annual recessions is illustrated for a Nepalese catchment in Fig. 7.

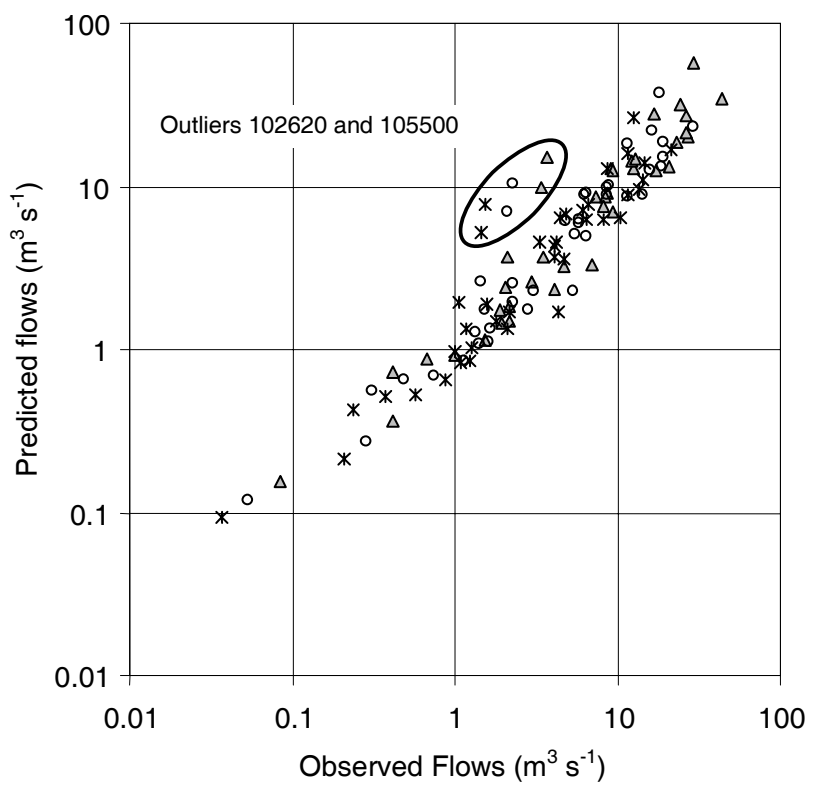

$\Delta$ Mid December $\circ$ Mid January $*$ Mid February

Fig. 6. Comparison of $10 \mathrm{~d}$ flow values from predicted and observed average recessions

\section{Conclusions}

Hydrological models predicting river flow during the dry season in the Himalayan region were developed successfully using a recession curve approach. A second order storage model was shown to be appropriate for most catchments and the assumption of zero inflows was concluded to be

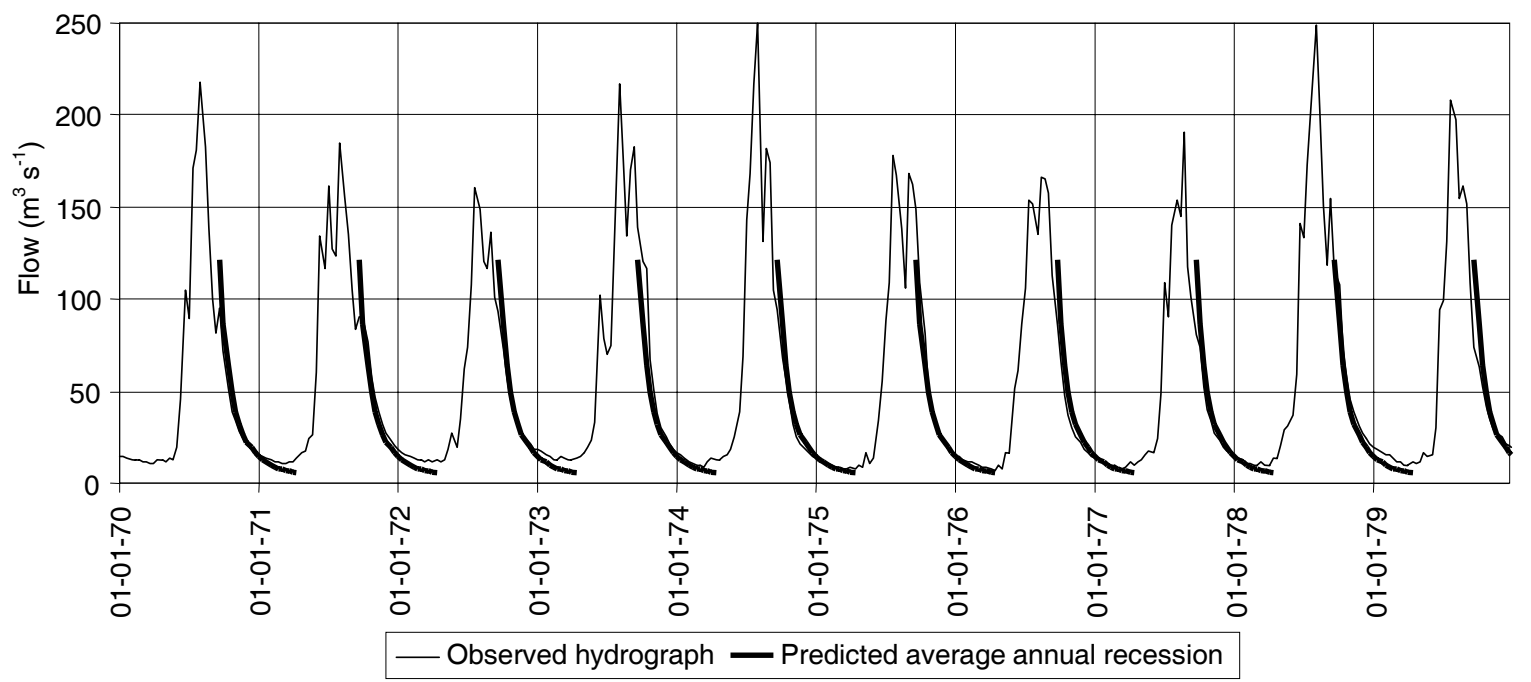

Fig. 7. Comparison of observed hydrographs with predicted average recessions for catchment 106600 
valid. Individual annual recessions were identified from long period, good quality flow records and the recession curve parameters were derived. An average annual recession was then defined by the average values of the three recession parameters $\mathrm{k}$ (recession constant), $\mathrm{Q}_{\mathrm{o}}$ (initial recession flow) and $\mathrm{T}_{\mathrm{o}}$ (the start date of the recession period). This averaging process retains the characteristics of individual recessions and minimises the impact of between year variability in recession behaviour.

Regional models enabled the recession parameters to be estimated for ungauged catchments using catchment characteristics. The models were tested using an independent evaluation data set of catchments and were relatively robust. However, the data set was still relatively small $(n=39)$ and cannot be regarded as representative of all conditions experienced in the Himalayan region. Future research should utilise data from other countries in the Himalayan region and additional information collected from the everexpanding hydrometerological networks in Nepal and Himachal Pradesh. This would improve the sampling of the hydrological and physiographical characteristics of the region and, hence, the understanding of recession responses in these catchments.

The regional models suggest the following relationships between recession behaviour and catchment characteristics;

- The recession constant $(\mathrm{k})$ is primarily dependent on catchment area, with smaller catchments showing steeper recessions. The datasets available did not allow relationships between the recession constant and hydrogeology to be identified. However, conceptually such relationships should exist and a field campaign designed to capture recession behaviour in small catchments with very different permeabilities would address this knowledge gap. For this reason, the application of the model to catchments with very different hydrogeologies to those represented in the data set should be undertaken with caution. Furthermore, larger data sets would need to be examined to assess whether the second order model was the most appropriate for all catchments in the region. The poor performance in catchment 102620 may have been due to an inappropriate choice of storage model or could be related to hydrometric errors in the data.

- The initial recession flow $\left(\mathrm{Q}_{\mathrm{o}}\right)$ is highly correlated with annual catchment runoff, with 'wetter' catchments having higher $\mathrm{Q}_{0}$ values. Because of high levels of uncertainty in rainfall datasets, the regional models for estimating $Q_{o}$ included no measure of catchment rainfall, which would be highly correlated with catchment runoff. Within Nepal, where better rainfall data were available, the importance of annual rainfall for determining $Q_{0}$ was evident. Improvements to the regional model for estimating the initial recession flow are likely to be realised if an improved and consistent characterisation of rainfall for the Himalayas is developed. Furthermore, the understanding of initial recession flows would be enhanced by the collection of flow data during these periods.

- The variability in the start date for recessions $\left(\mathrm{T}_{\mathrm{o}}\right)$ was effectively described by a model including geographic location and average catchment elevation. The relationships suggest that recessions begin earlier in the western Himalayas, where the preceding monsoon season is less severe, and earlier at higher elevations, which also experience lower intensity monsoons due to orographic lifting over sucessive mountain ranges. The within-year variability of $\mathrm{T}_{\mathrm{o}}$ was relatively low for a given catchment and local knowledge could be used to build up a better understanding of the spatial distributions of recession start dates across the region. The AVE_ $T_{0}$ value estimated from the regional model is suitable for use in planning the timing of field campaigns to capture $Q_{o}$ and to quantify recession behaviour.

Given the limitations of the data sets and the regional models, their performance for estimating long-term annual recessions was surprisingly good. The average error $\left(\mathrm{BIAS}_{\mathrm{voL}}\right)$ in estimating the volume of water flowing from a catchment over the period 1st of October and the 1st of February was $-8 \%$ and the volume was estimated to within $\pm 25 \%$ for 20 catchments, and to within $\pm 50 \%$ for 33 of the 39 catchments. The prediction of the mid-January flow (Jan 11 th), in cumecs, was within $\pm 50 \%$ of the observed value for 31 of the 39 catchments, and the average absolute error expressed as an equivalent depth $\left(\mathrm{ABSERR}_{\mathrm{DEPTH}}\right)$ was less than $5 \mathrm{~mm}$ for 27 of the catchments.

The development of models for estimating the average annual recessions provides water resource managers with the ability not only to estimate the magnitude of flows in ungauged catchments, but also the timing of these flows. This represents significant advantages over techniques such as flow duration curve statistics, for example WECS, (1990) and Singh et al., (2001) which lose the information regarding the temporal sequencing of flows. Hence, recession curve prediction is particularly well suited for application in the management of irrigation-type schemes, where water use can be matched to crop growth requirements at the various stages of the agricultural calendar. 


\section{Acknowledgements}

This research was funded by the United Kingdom Department of International Development as part of the UK's contribution to the International Hydrology Programme of UNESCO.

The authors gratefully acknowledge the assistance provided by the staff from the Department of Hydrology and Meteorology (Nepal) and the Alternate Hydro Energy Centre at the Indian Institute of Technology, Roorkee (IITRoorkee); this was essential for the hydrometerological data collation and fieldwork portions of the project. The assistance of the Department of Earth Sciences at IITRoorkee and the MENRIS department of the International Centre for Integrated Mountain Development (ICIMOD), Nepal, with spatial data collection was also much appreciated.

\section{References}

Boorman, D., Jenkins, A. and Collins, R., 1996. Rainfall-runoff data and modelling in the Likhu Khola catchment, Nepal. Conf. Proc. Ecohydrology of High Mountain Areas - Kathmandu, March 1996. 139-143.

Boussinesq, J., 1877. Essai sur la theorie des eaux courantes: Du mouvement non permanent des eaux souterraines. Acad. Sci. Fr. 23, 252-260.

Chalise, S.R. (Ed.), 1996. Climatic and Hydrological Atlas of Nepal. ICIMOD. Kathmandu, Nepal.

Delft Hydraulics, 1995. The study of seasonal availability for surface water for irrigation development in the western part of Nepal. Final Report, Delft Hydraulics, Netherlands.

Demuth, S. and Schrieber, P., 1994. Studying storage behaviour using an operation recession method. In: Proc. Braunschweig Conf., October 1993. Flow Regimes from International Experimental and Network Data (FRIEND). IAHS Publication no. 221, 51-59.

Ding, J.Y., 1967. Flow routing by direct integration method. Proc. Int. Hydrology Symp., Fort Collins, USA. 1, 113-120.

Dooge, J.C.I., 1973. Linear theory of hydrologic systems. Tech. Bull. 1468, Agric. Res. Service, US Dept. Agric., Washington, USA. $327 \mathrm{pp}$.

Food and Agriculture Organisation of the United Nations (FAO), 1999. Water Report 18: Irrigation in Asia in Figures, Food and Agriculture Organisation of the United Nations, Rome, Italy. $228 \mathrm{pp}$.

Gill, M.A., 1976. Exact solution of gradually varied flow. $J$. Hydraul. Div., ASCE, 102, HYD9, 1353-1364.

Gill, M.A., 1977. Algebraic solution of the Horton-Izzard turbulent overland flow model of the rising hydrograph. Nord. Hydrol., 8, 249-256.

Hall, F.R., 1968. Base flow recessions: a review. Water Resour. Res., 4, 973-983.
Harlin, J., 1991. Development of a process oriented calibration scheme for the HBV hydrological model. Nord. Hydrol., 22, $15-36$.

Horton, R.E., 1945. Erosional development of streams and their drainage basins: hydrophysical approach to quantitative morphology. Bull. Geol. Soc. Amer., 56, 275-370.

ICIMOD, 1996. Climatic and hydrological Atlas of Nepal. International Centre for Integrated Mountain Development, Kathmandu, Nepal. 1996. 264pp.

Kansakar, S.R., Hannah, D.M., Gerrard, J. and Rees, G., 2002. Flow regime characteristics of Himalayan river basins in Nepal. In: Proc. Fourth Int.FRIEND Conf., Cape Town, South Africa, IAHS Publication no. 274, 425-432.

Kinsel, W.G., 1963. Baseflow Recession Analysis for comparison of drainage basins and geology. J. Geophys. Res., 68, 36493653.

Mansell, M.G. and Johnson, J.C., 1994. Recession characteristics of small streams in the Eastern Districts of Zimbabwe. Proc. Inst. Civil. Eng.- Water, 106, 71-70.

Moore, R.J. and Bell, V.A., 2002. Incorporation of groundwater losses and well level data in rainfall-runoff models illustrated using the PDM. Hydrol. Earth Syst. Sci., 6, 25-38.

Pereira, L.S. and Keller, H.M., 1982. Factors affecting recession parameters and flow components in eleven small Pre-Alp basins. IAHS Publication no. 138, 233-242.

Rees, G., Croker, K., Zaidman, M., Cole, G., Kansakar, S., Chalise, S., Kumar, A. and Singhal, M., 2002. Application of the regional flow estimation in the Himalaya region. IAHS Publication no. $274,433-440$.

Singh, P., Jain, S.K. and Kumar, N., 1997. Estimation of snow and glacier melt contribution to the Chenab river, western Himalaya. Mt. Res. Dev., 17, 49-56.

Singh, R.D., Mishra, S.K. and Chowdhary, H., 2001. Regional flow duration models for large number of ungauged Himalayan catchments for planning microhydro projects. J. Hydrol. Eng.ASCE, 6, 310-316.

Tallaksen, L.M., 1995. A review of baseflow recession analysis. J. Hydrol., 165, 349-370.

Thapa, K.B., 1993. Estimation of Snow-melt runoff in Himalayan catchments incorporating remote sensing data. IAHS Publication no. 218, 69-74.

United States Geological Survey (USGS), 1996. GTOPO30, Global 30 Arc Second Elevation Data. USGS National Mapping Division, EROS Data Centre. http:/edcdaac.usgs.gov/gtopo30/ gtop30.html.

Vogel, R.M. and Kroll, C.N., 1992. Regional geohydrologicgeomorphic relationships for the estimation of low-flow statistics. Water Resour. Res., 28, 2451-2458.

Water and Energy Comission Secretariat (WECS). 1990. Methodologies for estimating hydrologic characteristics of ungauged locations in Nepal. Vols 1 \& 2. HMG Nepal, Ministry of Water Resources, Water and Energy Commission Secretariat and Department of Hydrology and Meteorology, Kathmandu, Nepal.

Werner, P.H. and Sundquist, K.J., 1951. On the groundwater recession curve for large watersheds. IAHS Publication no. 33, 202-212.

Wittenberg, H., 1994. Non-linear analysis of flow recession curves. FRIEND Flow Regimes from International Experimental and Network Data. IAHS Publication no. 221, 61-67. 